Article

\title{
A Study on Changes to the Form of Children's Playgrounds in Japan by Analyzing the JILA Selected Works of Landscape Architecture
}

\author{
Qing Qin ${ }^{\circledR}$, Kazuhiko W. Nakamura *(D), Kiyotatsu Yamamoto and Akio Shimomura \\ Department of Forest Science, The University of Tokyo, Tokyo 113-8657, Japan; iamqinqing@gmail.com (Q.Q.); \\ kiyo@fr.a.u-tokyo.ac.jp (K.Y.); shimo@fr.a.u-tokyo.ac.jp (A.S.) \\ * Correspondence: nakamura@fr.a.u-tokyo.ac.jp; Tel.: +81-3-5841-5208
}

Received: 7 March 2019; Accepted: 5 April 2019; Published: 10 April 2019

check for updates

\begin{abstract}
The aim of this study is to present the varieties of changes to children's playgrounds over the past 26 years, depicting the stages of the design process in designing playgrounds based on an adult perspective to encourage children to play more in today's changing society. Fourteen Japanese selected works from 1992 (first issue) to 2018 (the latest issue) were chosen for analysis. By analyzing the titles, descriptions, ichnographies, photos, and critical design reviews, the form of and changes to children's playgrounds are revealed in this paper. Results show the quantitative trends and qualitative changing patterns related to children's play. Daily physical playing was considered crucial in the first decade of the 1900s. In the 2000s, natural education activities were given more importance, while in recent years exercise play and variety of play have been given more attention. According to the results, we have to consider not only the richness of daily playing facilities, but also the broader aspect of playability, more than just including natural elements into designs, or increasing the variety of play styles. The different ways children enjoy play and the future design trends are also discussed in the last part of the article. Changes corresponding to the improvement of technology should be made to make playgrounds more attractive for children. This study could serve as a design reference for professionals.
\end{abstract}

Keywords: changes to children's playgrounds; future design trend; planning of playgrounds; JILA selected works of landscape architecture; designer perspective; playability; variety of play; play-image

\section{Introduction}

Children's play spaces and opportunities are under threat due to the ongoing processes of urbanization and its associated neoliberal spatial practices. Planned playgrounds and other kinds of open spaces near homes, schools, or other children's life circles are still the main play spaces in urban cities. However, children constitute a marginalized group, as they are often neglected in decision-making procedures with regard to urban planning. Wan Hee Kim (2018) [1] describes the importance of outdoor playing in the city and demonstrates that children are the primary agents of urban play.

Children's play has an important role in urban society, and professionals, designers, or planners also pay adequate attention to building or enhancing attractive playgrounds. It suggests that children's activities cannot be confined to a designed playground. Frost (1992) [2] introduces the concept of "playscape" for describing different play environments in urban planning. Children's playscape is defined as the landscape where children are able to play-and this definition stretches far beyond the boundaries of the playgrounds (Cunningham and Jones, 1999) [3]. It tends to clarify the importance of play. 
Based on field research that seeks to determine the actualities of children' play, children's play and space are classified variously and analyzed in several papers related to play. It is necessary to create a space that encourages diverse styles of play in parks and other urban play areas. Several studies have recently reported that significant differences exist between space characteristics including nature-intimate plays and those including other kinds of play. The presence of playground equipment and artificial plazas tends to negatively affect the diversity of natural play. The existence of natural elements, such as a lawn and dead leaves or contact with animals, has been proved to induce various kinds of play [3-6]. In other words, researchers, urban designers, and landscape architects have already recognized the importance of including natural elements into design drawings all around the world.

In Japan, research and urban design related to the play of children are almost systemic. Although they are more developed than those of other Asian countries, there are still some new, unnoticed problems that have gradually emerged with the development of society. Since the high-growth period, the structure of the family in Japan has changed, as the trend toward nuclear families has increased and families have grown smaller. There is also an increasing number of women choosing to work outside the house instead of investing all their energy into staying at home to look after the kids, going against the Japanese traditional social division of labor. Along with the development of compact cities, the declining birthrate and an aging population with the addition of declining local communities, very attractive electronic games, reduced play with family members at home, and the lack of play spaces for children, the situation related to children's play should be dealt with seriously in order to nip this trend in the bud to set an example for other countries, especially Asian developing countries.

As the living environment changes rapidly with economic growth, so do children's play environments. Over the past 30 years of economic development, more parks and squares have appeared as part of urban renewal and sprawl in Japan. A survey on the playing conditions of children in urban parks was first conducted in 1925 [7]. A book, "Planning for Play," written by Lady Allen of Hurtwood, was translated into Japanese and published in the 1970s. It introduced and promoted the concept of the adventure playground. Then, the landscape designs of planning researchers, designers, and architects shifted their focus to play environments [8,9], play elements, characteristics of play space, safety play, etc. [10], to set up the theory system of children's play [11] with regard to aspects of design and urban planning in the 1980s. After establishing the system, landscape evaluations of children's play, as well as proposals, advice, and attempts—such as developing "child-friendly cities" and "the ecology of play and the town" attracted extensive interest [12]. In the past 20 years, considerable attention has been paid to community play, nature schools, nature educational activities, etc. Intergenerational communication or events, creating a shared space with the elderly, and regional activation related to children have also received increased attention since the 2000s, while wild, adventurous, family-style, natural play areas have been built simultaneously in Western countries. Topics related to children are valued seriously, because Japan has been facing a declining birth rate and an aging population.

With changing ages, the methods of play are also changing. Meanwhile, the characteristics of play space are changing diversely. Several reviews clearly indicate the relationship between play types and space elements. Earlier studies $[6,13]$ reveal that 30 years ago, children engaged in a great variety of play in rural and natural spaces, while present-day children are engaging in monotonous and determined play, which are influenced by residential play equipment areas at established spaces. There are also many studies and surveys on the influencing factors or elements of children's play and playgrounds. However, little is known about the consideration of designers of urban parks or open spaces, even though design awareness is changing with the passage of time. The considerations of designers often play a great role because they are an important part of design evaluation, as feedback as Figure 1 displays, made by referring to the figure: "Seven guidelines for designing spaces that are comfortable for both children and adults" (p19) in the book "Designing Spaces for Children and Adults [Bilingual]," written by Ayako Naka + TeamM [14]. Therefore, it is necessary to make clarify the position and perspective of designers. 
With regard to efficient design today, simple and crude additions of natural elements, such as plants, waterside facilities, or artificial playground equipment, are cursorily included into the design drawings to increase the variety of play. This clever and straightforward approach should be recognized as a shortcut to quickly achieve design goals. However, is it really making spaces for children fun and enjoyable while playing? There is rational concern that the variety of play types is not the same as the playability according to the viewpoint of children; therefore, it is treated separately in this study. Landscape architecture designers should pay greater attention to this in order to enhance children's interest and to make their play more fun than for just developing a diversity of play styles or a variety of play categories.

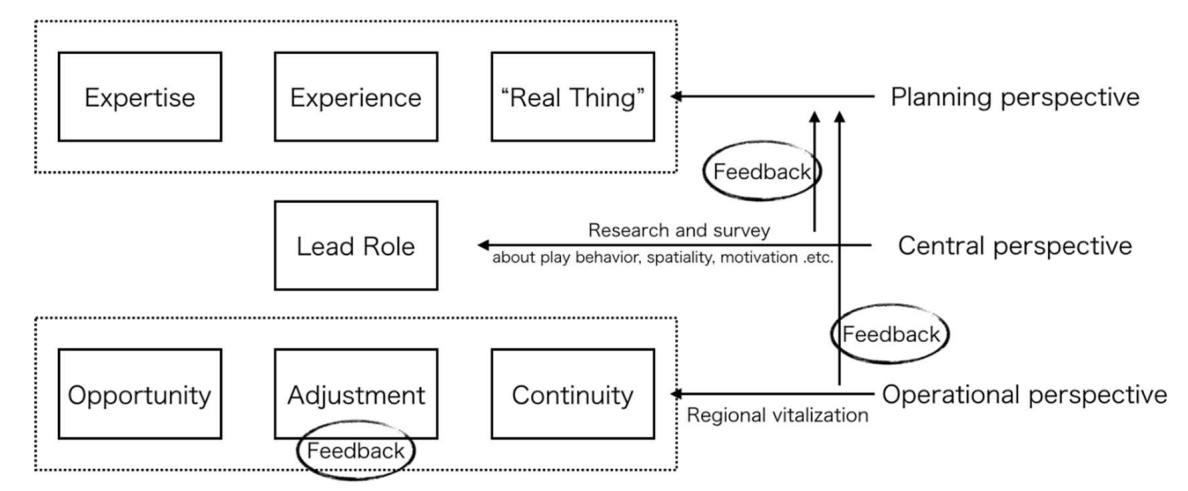

Figure 1. The flow of perspective in the design or planning of playgrounds.

Therefore, this paper focuses on children's play and playgrounds for reasons of scope within the consideration of designers, as well as for the reasons listed above. This study is designed to assess the role of consideration of designers while designing or planning urban open spaces for children. It aims to determine what elements or other design methods should be chosen while designing spaces for children to play and enjoy themselves thoroughly. The purpose of this study is to clarify how designers' considerations have changed over the decades. The field of study on children's play is still facing an ongoing challenge, requiring further research, and it is worthwhile to devote much effort to this as well as the new problems that arise with the development of society and technology.

\section{Literature Review}

\subsection{Relationship between the Types of Play and the Characteristics of Play Spaces}

Confronting the intensive relationship between children and urban spaces under the onslaught of modern urban development, many studies focus on the behavioral characteristics of children and the spatial characteristics of the play area in redeveloped urban areas where old and new buildings coexist or where new city planning blocks for revitalizing the community are prevalent.

The analysis of the literature of different types of playgrounds and kinds of play reveals insights into the ways in which communities, and sometimes children themselves, are attempting to overcome the paucity of play opportunities in the city. The literature produced by architects and urban or landscape designers has helped in estimating urban design to create more interesting parks or living spaces, but most of the methods used are qualitative, and most of these studies individually consider the types of play and spatial characteristic. With regard to the concept of creating a sense of place (SOP) [15] in the urban design field, Norberg-Schulz [16] believes that SOP could be best described as a three-dimensional spatial organization: "Space denotes the three-dimensional organization of the elements which make up a place, and character denotes the general atmosphere which is the most comprehensive property of any place. So does the children using space in the urban. It is suggested that, after setting up the children's play and practice theory system, designers should not just focus on the actual conditions of play, natural education, spatial distribution, or the single level of psychology 
or space. More attention should be paid to creating the kind of space that serves as amusement and is a fun atmosphere, to explore the correlations among them or some fuzzy field, rather than creating a tough division into play behaviors and space characteristics. In the meantime, playability should be considered along with the perspective of children to solve the problem of shrinking play equipment or play areas, as children are being lured away by electronic games as a result of social development.

\subsection{Outdoor Play Activities in Urban Areas}

Outdoor playgrounds serve as gathering points for people from a diverse range of generations, including infants, elementary and junior school students, parents, and other child-rearing circles. Certain parks or playgrounds developed by great designers provide an advanced vision of space that encourages rapport and communication between various people through children's recreational activities.

Some studies analyze the behavior of children to discuss the effects and benefits for children's play activities. A study by Ko Senda (2005) [17] concluded that play activities, including dynamic play and static play, have been carried out diversely and evenly among all children, regardless of different grades or gender differences, due to spatial creation encouraging natural and quiet play. Children use the general parks of Japan according to age brackets as revealed by Mari Yamamoto et al. (1999) [18]. Masato Ohono et al. (1998) [19] in their research also propose by hearing investigation that the percentage of type classification of actual situations of children in park varied by the peculiarity of the park, inclination of children's parents, the location of the park, recognition of areas near the park.

The extraordinary play condition in Japan is discussed regularly with regard to the decreasing winter outdoor play activities in snowy and cold regions, children's consciousness of the changes, and the planning for indoor playgrounds in parks. Shuowen Tseng et al. (2004) [20] proposed that the frequency of outdoor play activities, as well as the willingness to play outside in winter, decreased during the 1990s. It is a structural problem beyond generation as a result of the influence of parental attitudes to children. A study by Seiki Tagawa (2007) [21] clearly indicates that indoor playgrounds should be designed based on the ages of children in winter and in snowy regions. It is meaningful that children of different ages gather in one place and can securely enjoy play activities all year round, while for the users across a wide range of generations, from infants to grandparents, it is an excellent way of gathering to play and enjoy themselves in regional community spaces given the declining birthrate and aging society in Japan. According to the findings of these previous studies, for the future planning with regard to winter playgrounds, it is necessary to recognize the importance of considering not only the facilities (tangibles), but also the management (intangibles) of these spaces.

\subsection{Play Environment and Other Play Spatiality}

From the perspectives of children, all space could be considered as playgrounds for leisure activities; therefore, many articles in literature not only discuss conventional spaces-playgrounds in parks, play areas in commercial facilities, schools, amusement parks, or theme parks like Disney Land-but also recognize that some grey zones like roads, nearby schools or houses, and other spatial distributions with multitudinous play elements constitute the play environment. The play environment is a learning and training environment that equips children to face the future with all the necessary life skills.

A study by Nao Saio et al. (2002) [22] indicated that in many public elementary schools, planning and improvement of outdoor spaces such as the athletic field, pond, flower garden, and trees have rarely been considered, compared to spaces inside the school. Since environmental spaces including natural materials are valuable for children, the ideal way to plan natural spaces is both quantitatively and qualitatively considered.

China and Japan are undergoing similar processes of modernization, having the similar trend of being countries with declining birthrates and aging populations and development problems of urban children's play space, which offers the value of reference. Xiwei Yang.et al. (2005) [23] investigated the 
characteristics of streets for children to play by an analysis of data from observation and interview surveys in Beijing. This shows that both the amount of generated play spaces and the amount of play-space generating spaces in the street can be predicted with a level of precision based on the number of accessible playable spaces, the width of the street, the total frontage of open places, and the number of interfering trees along the street. Yao Shen, Isami Kinoshita (2011) [24], and Naoko Saio, Natsuya Hase (2007) [25] also evaluated the play environment both in Beijing and Japan, which showed that there is a trend that thoughts about road safety are more deficient than those about the expansion of play space. With regard to the location relationship with residence buildings, the mainstream of public green space zones is an enclosed type, which can be considered a condition of "being seen" and is good for play safety.

The number of studies on the relation between the physical environment and usage of parks mainly focus on specific age groups, such as children [26]. These results complement those reported by Young-sam YUN et al. (2003) [27] who propose using patterns of space and the place to stay based on time, school year, and sex of users; the details and function of environmental factors are based on the time of use and users; renovation to provide variety through the use of different kinds of environmental factors enlivens the space; additional environmental factors, such as living things and various surfaces of land, can all enhance the flexibility and variety of space. Findings from other studies also reflect similar points.

\subsection{Variety of Play}

The current play of children faces the problem of becoming monotonous and of play environments becoming scarce in artificially compact cities. A study by Kyung-Rock Ye (1995) [6] clearly indicates that in earlier days (30 years ago), children engaged in a great variety of play in rural and natural spaces, while current-day children are engaging in monotonous and determined play, which is not influenced by the characteristics of residential areas at established spaces in both urban and rural settings.

Many studies $[4-6,12,13,18]$ focus on nature observation of play, which mainly relates to the ages of children. The obtained detailed results are as follows: as children grow up, their senses and elements of recognition of wildlife through nature trails or natural contact change: younger children are particularly sensitive to sight or sound, while older children are not [28]. Through child play, children get into contact with various natural spaces such as the mountains, rivers, and lakes [29]. Significant differences exist between space characteristics inducing nature-intimate plays and the characteristics with other no-nature-intimate plays [4]. It is also an efficient way to encourage the variety of actualities of children's play (especially of nature-intimate play), to add more natural elements while designing urban parks. Nature experience facilities [30], as an integration base for regional innovation creation, also play an important expected role in increasing children's social learning and motivation to explore. It is possible to improve the quality of exchanges among children or among generations where local problem solving is expected in Japan, such as the problems of an aging society with its low fertility rate, the shortage of children's play areas due to the modernization of the city, and so on.

As a precondition that adults always believe, improving "playability" can create an excellent play environment for children and encourage children to play more. Most ways to improve the diversity of play, obtained from various kinds of research results, are focused on adding natural elements and on the existence of composite play, as the urban designers suggest. However, is there any other way to improve playability? Is there any other way to improve the diversity of play?

\subsection{Summary}

These works focus on aspects of children's play that have certain duplicate parts: the variety of play types, their spatial characteristics, the relationship between them, the play environment, and so on, which could not be clearly and simplify separated and classified. In total, "play" can be processed by different phases from different kinds of perspectives, channeling the qualitative differences and various changes in a certain direction. These articles all consider the designers and researchers as 
a whole, but in fact there are still many chasms and non-synchronizations (lagging or in advance) between practitioners and theorists. There are few papers on the changing consideration of designers (practitioners). This paper is based on this consideration to carry out research.

\section{Aims and Objectives}

Landscapes have not only been an object of utilitarian value but also a scene for outdoor life and leisure activities in Norway [31], Japan, and many other countries. As an important part of outdoor life, landscape designers also focus on how to create a composite space that can satisfy several functions to make children's play engaging and varied. The study explores this topic, aiming to clarify how urban designers in Japan manipulated children over the past few decades. On the other hand, it is also important to bridge the gap between Japan and other countries with developed playgrounds, such as Denmark and Sweden, and make children's play wild and open, rather than being too fearful of security issues or following a conservative path to design parks or other open spaces. Perhaps, it is the revolution of changing the ways of playing and playgrounds at present.

This paper aims to clarify the relationships between children's aspects of playing and spatial characteristics of playing zones in terms of designers' considerations, as well as the changing trends and patterns over the past few decades. For this purpose, by analyzing good design works, drawings or texts representations are executed for data of works that have different spatial characteristics such as area size, park type, the way of playing, conditions of playing zones, and so on. In the analysis, attention is paid to "playing factors" and "space factors."

In order to describe the perspective of designers while designing for children, the word "Play-Image" will be presented first in this article, which depicts the play atmosphere combining the aspect of playing (the Play Style) and spatial characteristic of playing zones (The Play Space). The concept of the "Play-Image" in this article refers to defining and explaining the "playing factors" and "space factors" together, which means everything can be played with or all activities are the objectives of play, and there is no special diversity of places in the children's world. Their behaviors and actions should comprise the play itself.

\section{Methods}

\subsection{Study Journal (Japanese Institute of Landscape Architecture (JILA) Selected Works of Landscape Architecture)}

A pre-survey revealed that comprehensive playgrounds in the parks designed by designers all across Japan in those 20 years, because of their diversity of play styles and play spaces, attracted more children than did other categories of small urban block parks [32-35].

In order to clarify the designers' consideration while designing for the children, the study involved selecting Japanese Selected Works of Landscape Architecture which is evaluated, appraised, and published by the Japanese Institute of Landscape Architecture (JILA). JILA is the most authoritative academic society in the field of landscape architecture in Japan, and it publishes authoritative yearly journals and magazines: Landscape Research Japan (ISSN 1340-8984), Journal On Line (ISSN:1883-261X), Technical Reports of Landscape Architecture, Selected Works of Landscape Architecture, and so on.

Based on planning or design by the regular members of the academic society, landscaping works are completed at the time of application registration; those that meet the selection criteria will be posted in the Selected Works of Landscape Architecture. Outstanding works are chosen yearly in Japan and published in the magazine, which plays a leading role in the field of landscape design in Japan and can serve as a reference for following designs or studies in the future. The Selected Works of Landscape Architecture have been published biennially since the first issue in 1992 to this year 2019, summed up in 14 books.

These excellent works of 14 books are A4 size, and each case is introduced in two pages, by typesetting or based on the layout of proposers to introduce their own design works. Selected works 
are roughly divided into the following parts: Management and Communication, Urban environment, Ecology, Office and Commercial space, Garden, Campus, Life, The Prize of JILA (design division), and so on. The categories are adjusted according to design popularity or the emphasis of the reviewers based on the year. Since works are designed and collected from the members of JILA academic society, the selected works are not limited to private classical gardens, open green spaces, or the size of the area. Instead, they include neighborhood parks, plans of the university campus, industrial parks, temporary Flower Festival Exhibition zones, metropolitan parks, sea life parks, residential districts, urban open spaces and so on. Most of these works are distributed in Japan, and there are also a small number of overseas works designed by designers living in Japan.

For this study, outstanding works were selected from 14 books of the Selected Works of Landscape Architecture. The total number of works is 604, including the annual awards, which are repeated. Except for the repeated works due to the award, the total number of works amount to 595. Works related to play or children were then extracted from those 595 works, resulting in a total of 173 works, which were summed up, as shown in Table 1. In order to eliminate accidents, for instance: children passing by in photos, children's appearance existed only in photos, meanwhile, any keywords related to children, kids, and play not mentioned in the text description or work titles were not included. The selected keywords included child, children, kids; play, playground, play area; school, children's park, kindergarten, and play equipment, such as slide, swings, jungle gym, and so on. Play equipment presented in drawings or photos were also counted.

Table 1. Works related to "play of children" of Selected Works of Landscape Architecture biennially.

\begin{tabular}{cccccccccccccccc}
\hline & $\mathbf{1 9 9 2}$ & $\mathbf{1 9 9 4}$ & $\mathbf{1 9 9 6}$ & $\mathbf{1 9 9 8}$ & $\mathbf{2 0 0 0}$ & $\mathbf{2 0 0 2}$ & $\mathbf{2 0 0 4}$ & $\mathbf{2 0 0 6}$ & $\mathbf{2 0 0 8}$ & $\mathbf{2 0 1 0}$ & $\mathbf{2 0 1 2}$ & $\mathbf{2 0 1 4}$ & $\mathbf{2 0 1 6}$ & $\mathbf{2 0 1 8}$ & \multirow{2}{*}{ Total 173 } \\
\hline Works Related to "Play" & 13 & 12 & 10 & 16 & 18 & 10 & 10 & 9 & 9 & 11 & 9 & 13 & 11 & 22 & \\
\hline
\end{tabular}

\subsection{Data Acquisition}

By extracting the works related to play or children, 173 works remained as the research objects and were turned into quantitative data. The form of every work in the Selected Works of LA included five parts: title, article, design drawing, photo and photo title, and works data (Figure 2) (Table 2). The comments from assessors of the article were also regarded as the city planners' or landscape designers' consideration, because they had similar design concepts and the same standpoints. Among the 173 works, aspects of Play-Image were counted based on parts of works as quantitative data.

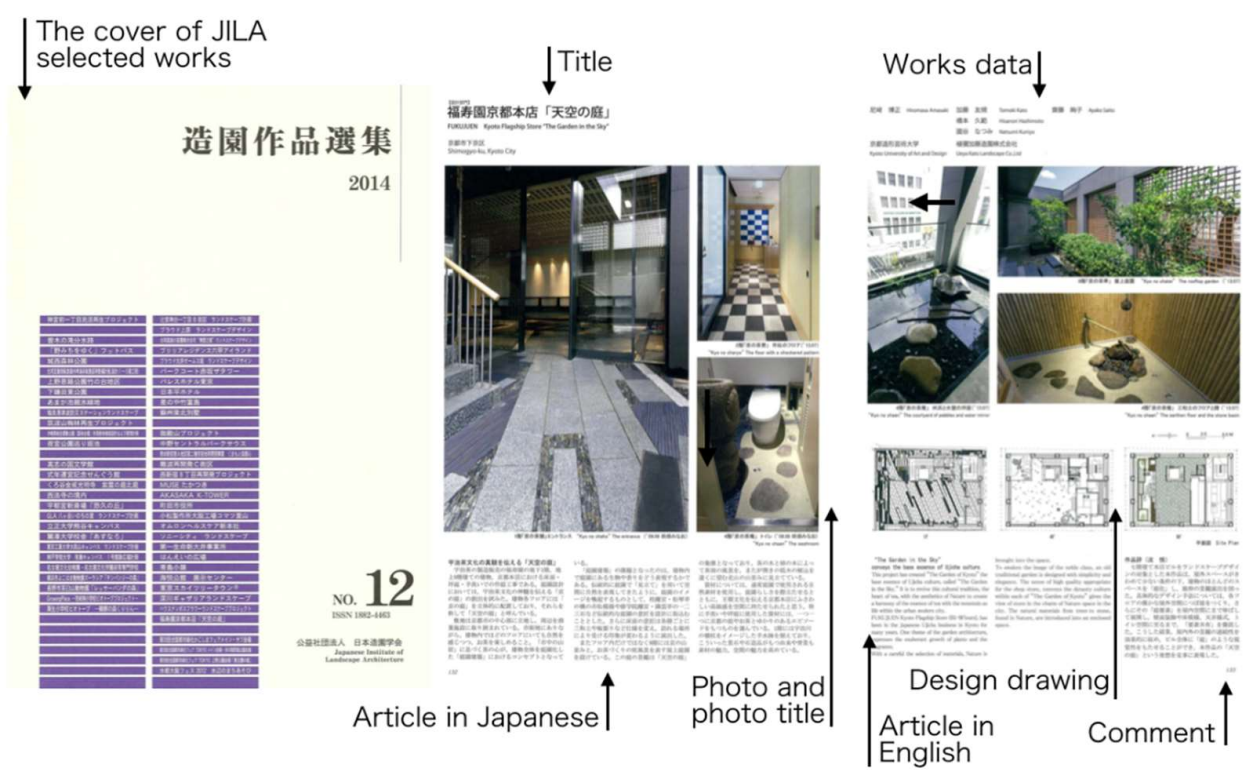

Figure 2. Parts of Japanese Institute of Landscape Architecture (JILA) Selected Works. 
Table 2. Contents of JILA Selected Works of Landscape Architecture.

\begin{tabular}{cc}
\hline Contents & Information \\
\hline Title & works location or case attribute \\
\hline Article & text description: designers' consideration including the comments from assessors \\
\hline Design Drawing & designer plan including ichnographies, elevations, legends, or concept maps \\
\hline Photo and Photo Title & usage situation for living \\
\hline Works Data & construction attributes \\
\hline
\end{tabular}

\subsection{Analysis Methods}

According to the diverse works of JILA Selected Works of Landscape Architecture, this research applied classified analysis to clarify the changes in play patterns, ways of playing based on space components, and the kinds of play the designers took into consideration while designing places over the past 30 years.

First of all, 173 selected works in 14 books were analyzed according to the Play-Image: ways of playing, and spatial characteristics. Their characteristics were translated into qualitative data. Then, by applying multivariate analysis (Quantification Theory Type III) [36,37], the qualitative data were included, thus producing the scores of 173 works in three axes. The three axes showed the new indicators to explain the play style and the play space (Play-Image), which integrated similar components together into the new indicators. Simultaneously, the changes of these scores' data based on ages by drawing the box-whisker plot from the multivariate analysis result were included in the analysis as the quantitative trends. Next, using these scores, the quantitative data, 173 works were classified into several groups by the cluster analysis method. Finally, the three new components in new Play-Image (the play style and the play space) axes of selected works were counted again according to the five types. The characteristics of several groups through the course of time could be clarified by the box-whisker plot as the qualitative changing patterns.

Before presenting the specific trends or changing patterns results, previous studies and applications using the method of Quantification Theory Type III and cluster analysis in the field of urban design and landscape architecture should be briefly introduced. Quantification Theory Type III is a kind of multivariate analysis, widely used in Japan as qualitative analysis. When the data (variables) are not specific values but instead are like the true-or-false type or the yes-or-no type, the yes-or-no data would be converted to 1 or 0 through this qualitative multivariate analysis. It is similar to the processing methods of principal component analysis and factor analysis in terms of organizing similar categorical variables together, but the cluster analysis aims to classify the similar cases or samples into several patterns. In Japan, various analytical methods are often used in combination. After Quantification Theory Type III, cluster analysis is generally used to summarize and classify the cases into several patterns, which is usually applied in research related to questionnaire investigation, landscape preference and evaluation, landscape view recognition, resident consciousness, and so on. For example, the aforementioned studies $[36,37]$ focus on the tendency of landscape users to provide various answers.

\section{Results}

\subsection{Categories of the Play-Image}

Referring to previous research with regard to the aspect of the relationship between the play and the space characteristics of playgrounds in Japan $[4,13,17,38,39]$, the importance of the natural elements in children's playgrounds $[5,6,23,29,40,41]$, and the extraordinary play conditions $[20,21,42]$ in Japan, including the child-oriented categories of the play and, separately, playing space, were presented through the eyes of the children and included playmates, play objects, play equipment; roads, parks, schools, homes nearby, and so on. However, there were few papers classified by designers' 
position combined with the play styles and space characteristics as the design elements. In order to describe the consideration of the designers, this study was performed to determine the use of the new concept-"Play-Image" by putting together these design elements to identify the relationship among them.

Classification related to Play-Image was focused on four components: Play Unit, Play Cultivation, Place Exclusivity, and Place Character. These components are represented in Table 3 as the aspects of the community and education/growth of the play, zoning or not in design and regional characteristics of the place. Each part mentioned above was classified into inferior categories, from Individual to Community, Physical Activity to Feeling, Scattered to Zoned, and Urban to Nature, representing 14 categories in total. The description and examples of 14 categories of Play-Image that existed in the selected works are represented in Table 4; they include Proximity, Family Unit, Educational Place, Regional Event; Exercise, Creativity, Feeling, Openness; Space Sharing, Position, Zoning; Urban Artificial, Secondary Nature, and Natural Land.

Table 3. Play-Image category components.

\begin{tabular}{|c|c|c|c|c|}
\hline \multicolumn{3}{|c|}{ Based on Consideration of Designers } & \multicolumn{2}{|r|}{ Components } \\
\hline \multirow{3}{*}{ Play-Image } & \multirow[b]{2}{*}{ The Play Style } & Play Unit & Photo; Article & play by community: Individual $\leftrightharpoons$ Community \\
\hline & & Play Cultivation & Photo; Article & $\begin{array}{l}\text { play with education/growth: Physical } \\
\text { Activity } \leftrightharpoons \text { Feeling }\end{array}$ \\
\hline & The Play Space & Place Exclusivity & Design drawing & play in zone or not: Scattered $\leftrightharpoons$ Zoned \\
\hline
\end{tabular}

Table 4. Play-Image components.

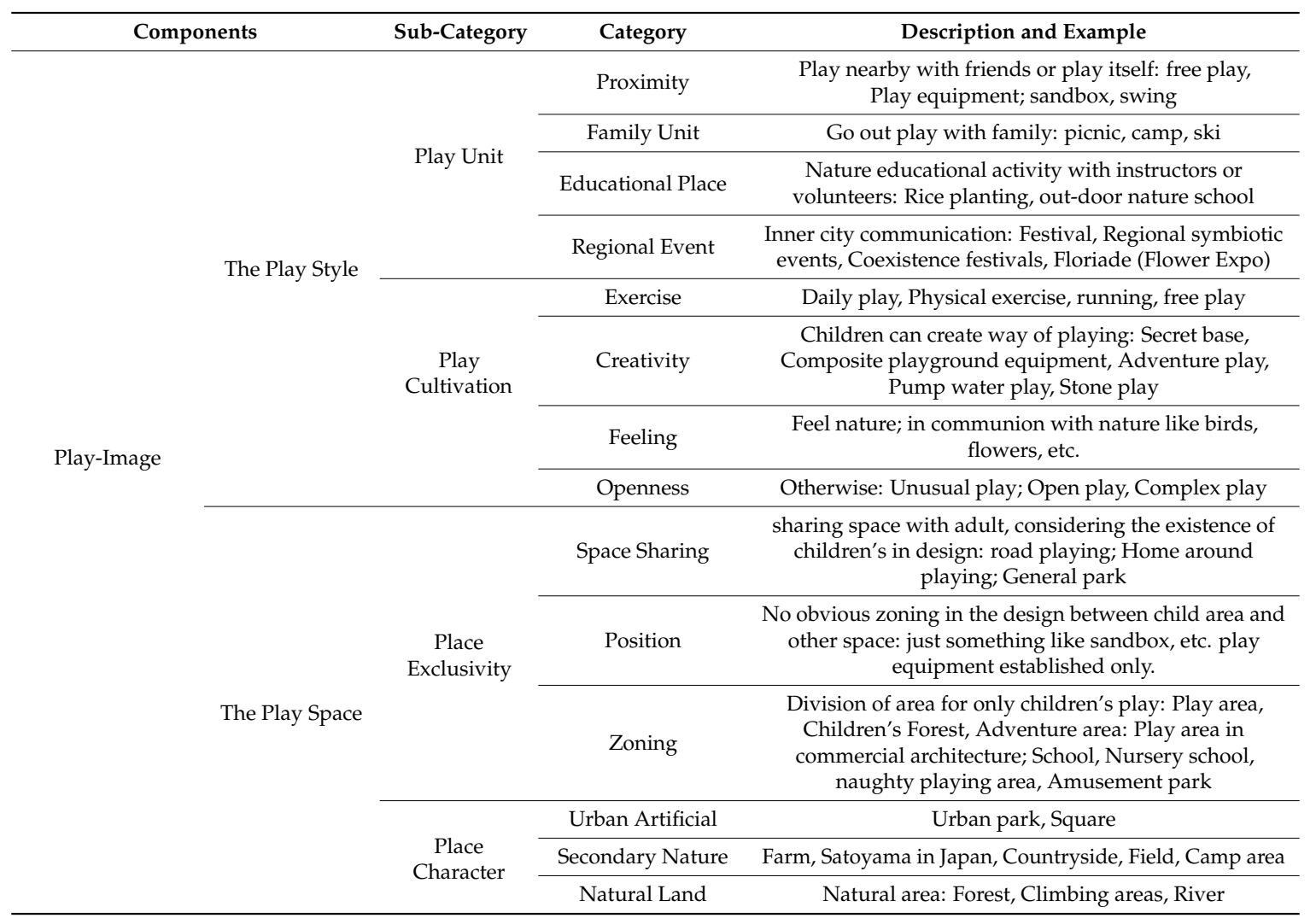

The four sub-categories were independent of each other because they were classified by different aspects related to children, play, or play space, which meant that one case from the JILA Selected Works of Landscape Architecture was divided into four sub-categories for quantization: Play Unit, 
Play Cultivation, Place Exclusivity, and Place Character. This meant that each case could be counted four times. Each category under each sub-category was also independent from the others which meant forming quantitative data with one from each of the four sub-categories.

Contents of the JILA Selected Works of Landscape Architecture included the Title, Article, Design Drawing, Photo and Photo Title, and Works Data. With regard to the text, including Titles, Articles, and texts portions of Drawing, Photo Titles, and Works Data, keywords were sorted into each category, as shown in Table 5. With regard to another part-figures-determining which cases did or did not represent zoning only for children, whether play equipment existed, whether there was no zoning but designed play equipment, and whether events or group activities existed, was based on the Drawings and Photos in the selected works. If there was a corresponding figure, the count was 1 , and if there was none, the count was 0 . In this way, selected words would be counted as qualitative data and could be classified or analyzed later.

Table 5. Keywords of Play-Image categories in the Selected Works.

\begin{tabular}{|c|c|c|}
\hline Categories & Detailed Description & Keywords Appearing in Selected Works \\
\hline Proximity & $\begin{array}{l}\text { Play subject is generalized, single play, } \\
\text { takeaway play tools or play with friends. } \\
\text { normal types of play in park nearby }\end{array}$ & $\begin{array}{l}\text { free play, relax, sitting, walk. watching over, sand box, swing, simple } \\
\text { play equipment like spring rider }\end{array}$ \\
\hline Family Unit & As a family outside playing & ski, picnic, camping, amusements park, sea resort, resort area \\
\hline $\begin{array}{l}\text { Educational } \\
\text { Place }\end{array}$ & $\begin{array}{l}\text { Nature educational activity with } \\
\text { instructors or volunteers }\end{array}$ & $\begin{array}{c}\text { zoo, botanical garden, garden tour, natural living experience, ecological } \\
\text { museum, natural ecological park, natural school, rice planting, flower } \\
\text { planting, plantation }\end{array}$ \\
\hline Regional Event & Inner-city communication event & $\begin{array}{l}\text { urban district communication, workshop, community, revitalize the } \\
\text { community, community, local event, Flower Expo, participation by } \\
\text { residents, Festival }\end{array}$ \\
\hline Exercise & $\begin{array}{l}\text { Daily physical movement; heathy } \\
\text { exercise; simple play equipment that } \\
\text { can be seen anywhere }\end{array}$ & $\begin{array}{c}\text { run, free play, after school, walk, water play in square, park of amenity } \\
\text { embankment, training equipment }\end{array}$ \\
\hline Creativity & $\begin{array}{l}\text { Adventurous play; Spontaneous play; } \\
\text { Athletic play equipment }\end{array}$ & $\begin{array}{c}\text { pump water play, stone play, composite playground equipment, } \\
\text { monument playground equipment, molding playground equipment, } \\
\text { combination playground equipment, cloud image equipment, } \\
\text { three-dimensional net playground equipment }\end{array}$ \\
\hline Feeling & $\begin{array}{l}\text { Immerse in the nature; feeling with } \\
\text { the nature }\end{array}$ & $\begin{array}{l}\text { flower/bird/animal touch, river, mountain, wet land, agricultural } \\
\text { experience, nature experience }\end{array}$ \\
\hline Openness & Otherwise & $\begin{array}{c}\text { participation production, handicapped child play, winter outside play } \\
\text { in north area, history learning, play of independence and voluntary } \\
\text { (playground pave), multi-purpose square }\end{array}$ \\
\hline Space Sharing & $\begin{array}{l}\text { No division in the plan view or } \\
\text { elevation; just taking children's play } \\
\text { into consideration }\end{array}$ & $\begin{array}{l}\text { regional childcare support nearby, road, green space, house nearby, } \\
\text { natural park, shopping district }\end{array}$ \\
\hline Position & $\begin{array}{l}\text { No clear division in the plan view or } \\
\text { elevation; just some play equipment } \\
\text { established only }\end{array}$ & $\begin{array}{l}\text { water pipe Art, stone play area, play equipment only, sculpture play, } \\
\text { go for a walk tour; monument play }\end{array}$ \\
\hline Zoning & $\begin{array}{l}\text { Clear division in the plan view or } \\
\text { elevation; division of area for only } \\
\text { children's play }\end{array}$ & $\begin{array}{l}\text { kid terrace, play area, forest of children, acorn forest of children, } \\
\text { adventure area, residential playground equipment, amusement park, } \\
\text { play equipment space, kindergarten/school/nursery school, } \\
\text { commercial facility play area, theme park }\end{array}$ \\
\hline Urban Artificial & Urban artificial & urban park, residential area play square, hydrophilic revetment in town \\
\hline $\begin{array}{l}\text { Secondary } \\
\text { Nature }\end{array}$ & $\begin{array}{l}\text { Natural environment created, managed, } \\
\text { maintained by human activities: } \\
\text { inter-mountainous area, etc. }\end{array}$ & $\begin{array}{l}\text { botanical garden, horticultural exposition, riverside village, terraced } \\
\text { rice-fields, reservoir, farm, ruins, agricultural experiment station, } \\
\text { remaining green farmland, woodland close to the village (Satoyama) }\end{array}$ \\
\hline Natural Land & $\begin{array}{l}\text { Natural area: not effected or built or } \\
\text { planed by human activities }\end{array}$ & $\begin{array}{l}\text { forest, climbing areas, river, nature observation park, nature park, } \\
\text { natural ecological park, natural oasis, wild bird park, regional protected } \\
\text { forest, preservation green space, scenic park, wet land }\end{array}$ \\
\hline
\end{tabular}

\subsection{Quantitative Trends}

At first the Play-Image components of the 173 cases were analyzed as qualitative data according to the 14 categories mentioned above. Then these qualitative data were analyzed further by Quantification Theory Type III. As a result, the contribution ratio was up to $48.6 \%$ to the third axes, as shown in 
Table 6. The quantitative trends of results were shown in Figure 3. Next, cluster analysis showed the several groups divided from the 173 works by analyzing the sample scores of 173 cases of three new axes in Table 7. The method of clustering was Ward's method and the measure of the interval was Euclidean distance. As shown in Figures 4 and 5, the 173 selected works were divided into five groups. At last, the qualitative characteristics of each group were determined according to three new axes, and the trends of qualitative characteristics in these decades were also inferred.

Table 6. Results from Quantification Theory Type III.

\begin{tabular}{cccccc}
\hline Axis No. & $\begin{array}{c}\text { Eigen } \\
\text { Value }\end{array}$ & $\begin{array}{c}\text { Ratio of } \\
\text { Contribution }\end{array}$ & $\begin{array}{c}\text { Cumulative } \\
\text { Contribution Ratio }\end{array}$ & $\begin{array}{c}\text { Name of } \\
\text { Axis }\end{array}$ & $\begin{array}{c}\text { Indicators' Interpretation for Axis } \\
\text { Interpretation (Negative/Positive) }\end{array}$ \\
\hline First Axis & 0.5589 & $22.4 \%$ & $22.4 \%$ & $\begin{array}{c}\text { Variety of } \\
\text { Play Types }\end{array}$ & Equipment play/Natural Elements Play \\
\hline Second Axis & 0.3377 & $13.5 \%$ & $35.9 \%$ & $\begin{array}{c}\text { Accessibility } \\
\text { of Play }\end{array}$ & Natural Activity Play Nearby/Distant Tour play \\
\hline Third Axis & 0.3182 & $12.7 \%$ & $48.6 \%$ & $\begin{array}{c}\text { Initiative of } \\
\text { Play }\end{array}$ & Exercise/Creativity \\
\hline
\end{tabular}

The scores of 173 works of three axes by Quantification Theory Type III showed the quantitative changes and the trends of these changes along with ages on the whole, while the five groups resulting from the cluster analysis of ages showed the qualitative changes and patterns.

First of all, the interpretation of data in three axes claimed the following according to the category scores (Table 7) from Quantification Theory Type III. It is the method used to combine the analogous categories into new categories(axes) judged by positive or negative scores in certain axis based on the benchmark of the meaning of this axis. Consequently, it is indispensable for naming the axis by plus and minus numerical values in one axis. By interpretation of axes, three new axes (latent variables) were derived from the 14 Play-Image categories (observation variables). In Table 7, the upper side (negative) of the First Axis is locational fun equipment play, which indicates few kinds of play types. The original categories are Creativity and Position. The lower side (positive) is natural elements play which implies a variety of play types, and the original categories are Feeling, Educational Place, and Secondary Nature. Therefore, the First Axis has been identified by "Variety of Play Types". The Second Axis has been named "Accessibility of Play," within the discrimination of natural events or play activities nearby (negative), like nature observation, and distant play activities (positive), like outdoor family tourism. Thereinto, in this axis, the obvious negative original category is Openness, while the positive original category is Family Unit. The Third Axis is used to distinguish the play of the physical body movement (negative) and creativity (positive), which is set as the discrimination axis of "Initiative of Play." The apparent negative category is Exercise, which leads to passive play. On the other side of this axis, the positive original categories are Position and Creativity, which offers active play.

Then, by creating a box-whisker plot, the Play-Image quantitative biennial trends along with time change could be presented. After setting the sample scores under the three new axes from the results of the Quantification Theory Type III into every other year (two years per book), sample scores' data were ordered from smallest to largest. By finding the five-number summary (the minimum, first quartile, median, third quartile, and maximum) of a set of every biennial year data, the box and whisker plot in three axes could be drawn, the trends of which are shown in Figure 3.

From the data in Table 6, Figure 3, the following Play-Image quantitative trends were derived: 
Table 7. Category scores from Quantification Theory Type III in three axes.

\begin{tabular}{cccccc}
\hline \multicolumn{2}{c}{ First Axis } & \multicolumn{2}{c}{ Second Axis } & \multicolumn{2}{c}{ Third Axis } \\
\hline Creativity & -1.443146 & Openness & -2.825095 & Exercise & -1.800892 \\
\hline Position & -1.433350 & Secondary Nature & -1.482523 & Space Sharing & -1.045178 \\
\hline Proximity & -0.913674 & Regional Event & -1.224779 & Urban Artificial & -0.383917 \\
\hline Urban Artificial & -0.545929 & Position & -1.117553 & Proximity & -0.300275 \\
\hline Exercise & -0.524196 & Urban Artificial & -0.311103 & Regional Event & 0.114991 \\
\hline Zoning & -0.413860 & Proximity & -0.064842 & Openness & 0.390904 \\
\hline Family Unit & -0.252772 & Space Sharing & -0.063339 & Zoning & 0.433130 \\
\hline Openness & 0.154354 & Educational Place & -0.021575 & Educational Place & 0.485305 \\
\hline Natural Land & 0.740552 & Exercise & 0.101950 & Feeling & 0.546422 \\
\hline Space Sharing & 0.853420 & Creativity & 0.126091 & Natural Land & 0.593560 \\
\hline Regional Event & 0.959481 & Feeling & 0.392649 & Family Unit & 0.609530 \\
\hline Feeling & 1.536565 & Zoning & 0.406055 & Secondary Nature & 1.268321 \\
\hline Educational Place & 1.592484 & Natural Land & 3.200469 & Position & 1.995807 \\
\hline Secondary Nature & 1.899077 & Family Unit & 4.078318 & Creativity & 2.184787 \\
\hline & & & &
\end{tabular}

First Axis

$\square 1992 \square 1994 \square 1996 \square 1998 \square 2000 \square 2002 \square 2004 \square 2006 \square 2008 \square 2010 \square 2012 \square 2014 \square 2016 \square 2018$

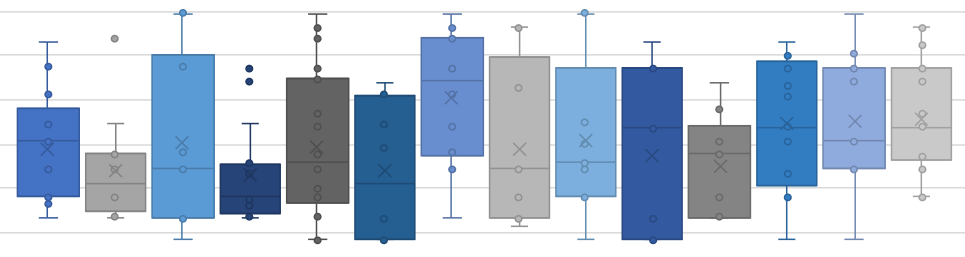

Second Axis

$\square 1992 \square 1994 \square 1996 \square 1998 \square 2000 \square 2002 \square 2004 \square 2006 \square 2008 \square 2010 \square 2012 \square 2014 \square 2016 \square 2018$

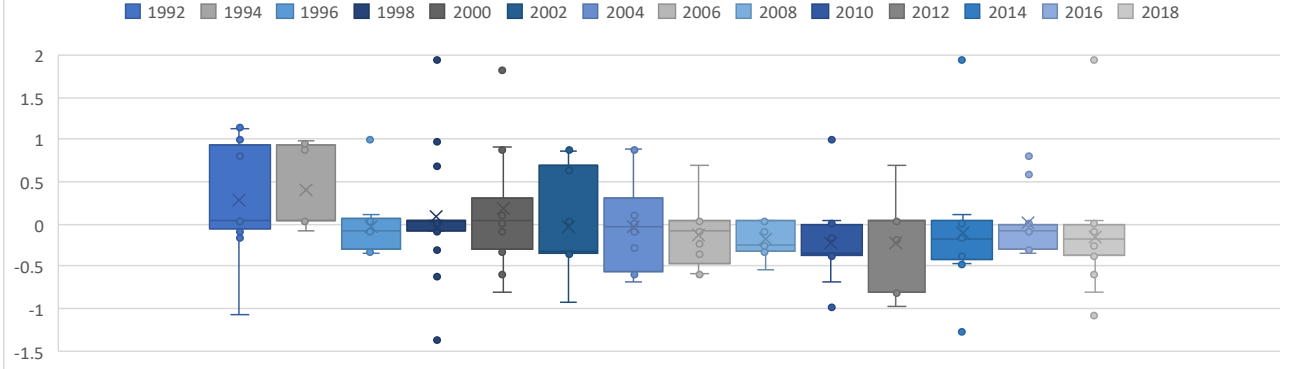

Third Axis

$\square 1992 \square 1994 \square 1996 \square 1998 \square 2000 \square 2002 \square 2004 \square 2006 \square 2008 \square 2010 \square 2012 \square 2014 \square 2016 \square 2018$

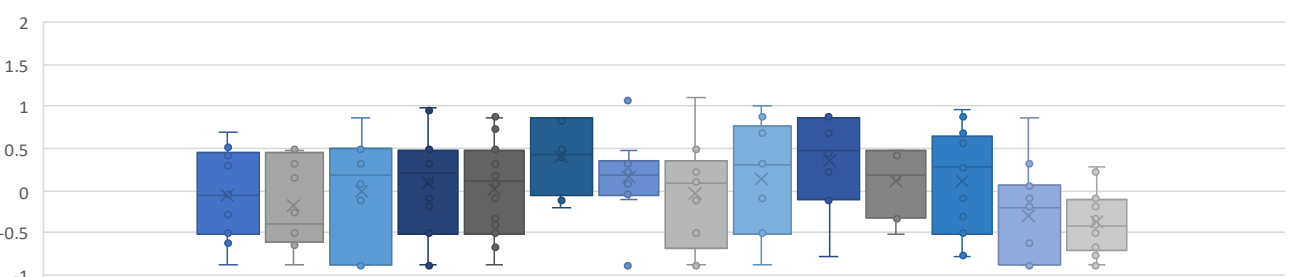

$-1.5$

Figure 3. The quantitative trends of three axes from 1992 to 2018 (sample scores). 
The First Axis, which relates to the variety of play types, presented an increasing overall average, which changed frequently and over a wide range over time for several decades. The whole was dispersed, while the part was concentrated. The increasing variety of play types in the design was clarified. Therein, the median numbers in each set of yearly data, the minimum, and the maximum varied within wide limits. The concentrated distribution scores were in the early 1990s, especially 1992, while dispersed over an extensive area in the 2000s, remaining extensive in the 2010s. Therefore, generally speaking, with the change in times, the variety of play types increased dramatically, and the degree of change (richness) of diversity also changed significantly.

In the second axis, which relates to the accessibility of play, it revealed the different directions of play. Except for the early 1990s and the early 2000s, the overall data distribution was negative, which suggested that people always preferred natural event play styles for children in their life circles near homes, houses, schools, parks, and so on in and around the city, instead of going out further on distance tours or travel with children. Therein, the median numbers in each set of yearly data, stayed consistent or remained largely unchanged, while, the minimum and maximum varied significantly, which indicated that the average play styles that people preferred to choose in daily life were always based on a similar situation. On the other hand, there were more discrete data than other axes, indicating that there were extremes in the choice of cases in the selected works. Except for the years 1992 and 1994, a decreasing trend was noticed with the passage of time. The most special year was 1998 with most discrete data, rarely concentrated but averagely distributed from the minimum and the maximum.

In the third axis, which relates to the initiative of play, it was indicated that with changes in time, several sets of yearly data were distributed roughly the same and varied slightly. Therein, the median value was stable and climbing up before 2002 and then declining after the year 2004, and the maximum was consistent from 1992 to 2000, while the rest showed irregular variations. It was clarified that the inclination of design works related to play or play space had changed from physical play activity to creativity play, and then back to physical play activity (as of 2018). On the other hand, there were not enough discrete data, which implies there were few extremes in the choice of cases in the selected works.

With regard to the view of combining three axes' variation distribution, the approximate age distinction for dividing times was based on the early 2000s, around 2002 and 2004. In addition to 1998, which had the most discrete data among each yearly set, instability and fluctuations were large in approximately five years of the early 2000s. A steady trend before and after this has been noticed. In the three-axis vertical comparison, the first axis and the third axis were almost of the same range in value, overall, while the value in first axis exceeded that of the third axis after the mid-late 2000s. The second axis had a lower average all along, except in the early 1990s, which meant that with regard to the designers' consideration, the variety of children's play types and the initiative of children's behaviors were far beyond the consideration of the accessibility of play.

\subsection{Qualitative Changing Patterns}

After the Quantification Theory Type III analysis of the quantitative trends of changing along with ages on the whole was conducted, the sample scores of 173 cases of three axes were grouped by cluster analysis. The method of clustering used was Ward's method and the measure of the interval was Euclidean distance. The 173 selected works were divided into five groups. Qualitative changing patterns could be observed by analyzing the characteristics of each group and then analyzing which group accounted for the majority every two years among these decades.

First of all, from the result of annual number of selected works by groups (grouping by cluster analysis), since the total numbers of selected works were inconsistent every two years, it was counted as a percentage within the year, and the percentage trends are shown in Figure 4. The general trends over time of each group were concluded as follows: 


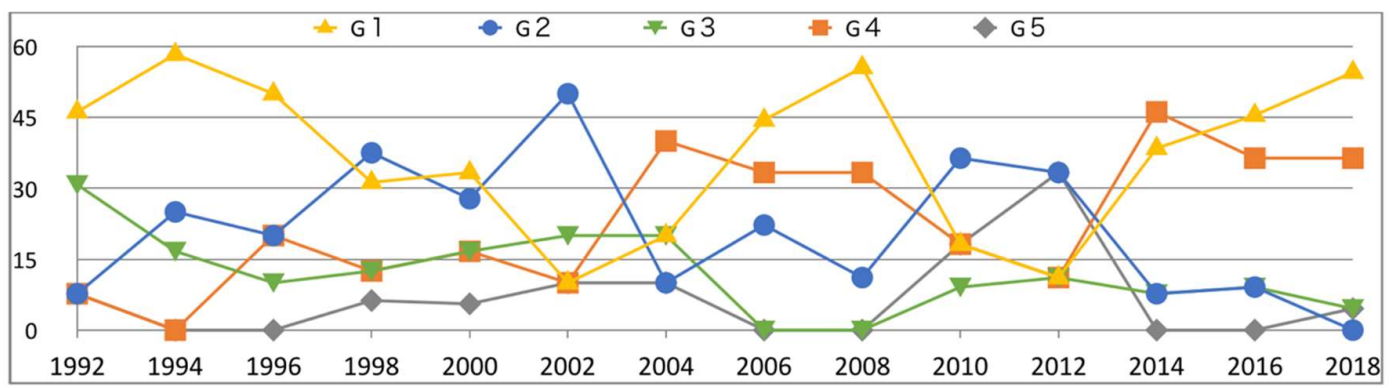

Figure 4. The trends of the percentage of each year in five groups.

The overall trend of Group one (G1) showed a cyclical trend of rising, falling, then rising and falling again, reaching the period's highest points in 1994, 2008, and 2018. Additionally, the overall numerical value was higher than that of the other groups. Group two (G2) showed an upward trend before 2002. After the early 2000s, it rebounded slightly twice in 2010 and 2012, but it showed a consistent downward trend and reached its lowest point in 2018. Group three (G3) has shown a smooth downward trend from 1992 to the present, and the overall numerical value was lower than that of other groups. Group four (G4) showed the tendency to rise through the passage of time. From the lower numerical value of the early 1990s to the higher value of 2018, it increased in magnitude. Group five (G5) stabilized the trend at a lowest value, flat but slightly fluctuating. However, there was a change of higher values around 2010 to 2012.

Then, the sample scores were assigned to each group of 173 selected works, by creating a box-whisker plot to analyze the data distribution in five groups. Using the distribution of the five sets of data in the three new axes, the distribution situation of each group was obtained. Combined with the definition and interpretation of the three axes (Table 6), the qualitative characteristics of each group based on the three axes could be elucidated. With the addition of the percentage trends of five groups under the various temporal changes, qualitative change patterns were obtained.

From Figure 5 and Table 8, the distribution of groups in each axis and the significant characteristics (weakest and strongest) of the five groups were summarized as follows: in the first axis, G4 and G2 are the two positive and negative terminals, which means that G4 comprises the most variety of play styles and G2 comprises the least variety. Besides, G3 and G4 are distributed as positive scores, while G1 and G2 have a negative distribution, and G5 is near zero. In the second axis, G3 is obviously and uniquely distributed in positive numeric values, which represent the playing tendency of remote tourism, travel, or sightseeing in the reachability of children's play. The other groups (G1, G2, G4, G5) are all distributed in the negative axis, which means that they tend to play naturally and softly with children near their life circle. In the third axis, G1 is also evidently distinguished from the rest (G2, G3, G4, G5), and distributed in the negative area, which signifies physical play, paying more attention to physical activities and behaviors for children. The rest of the groups also have a positive or intermediate zero tendency, with the highest numeric value of G2 representing creative play to make play more fun and enjoyable for children through the use of modern technology in play equipment or based on designers' whims. 


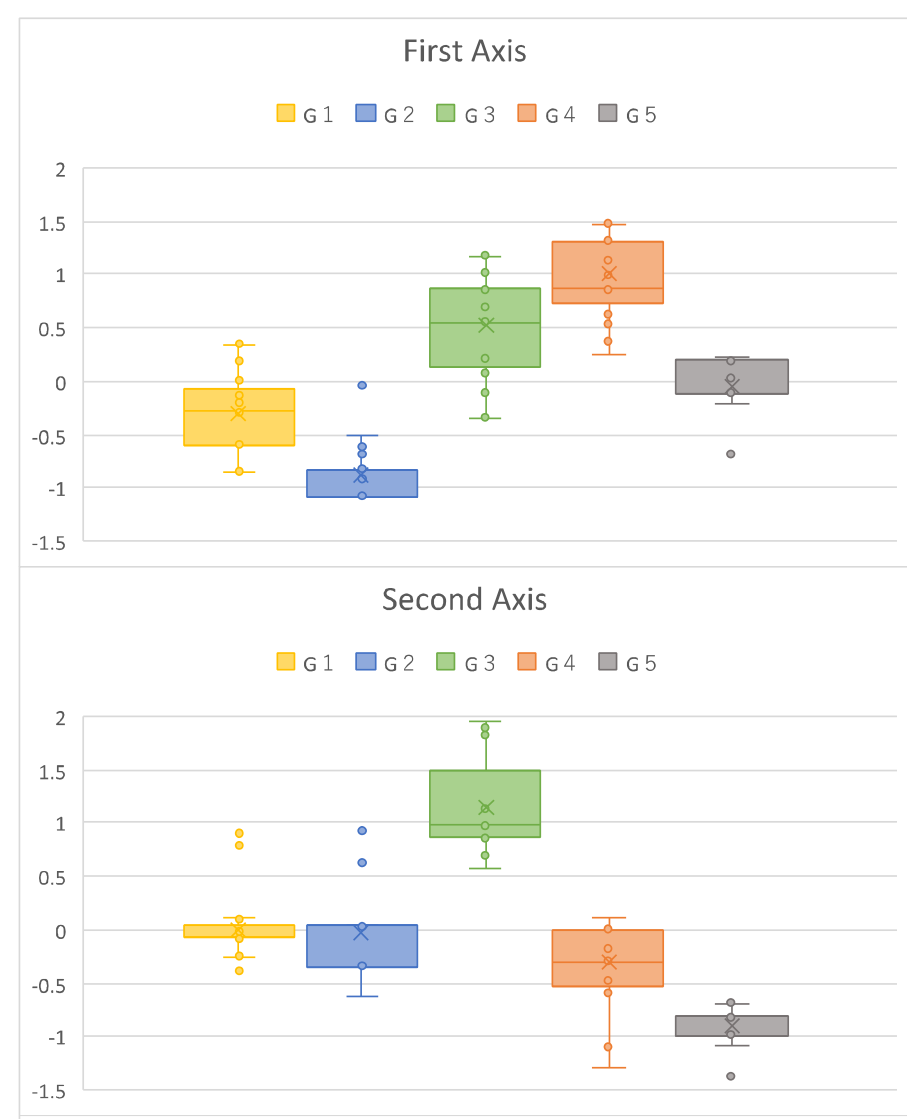

Third Axis

$\square \mathrm{G} 1 \square \mathrm{G} 2 \square \mathrm{G} 3 \square \mathrm{G} 4 \square \mathrm{G} 5$

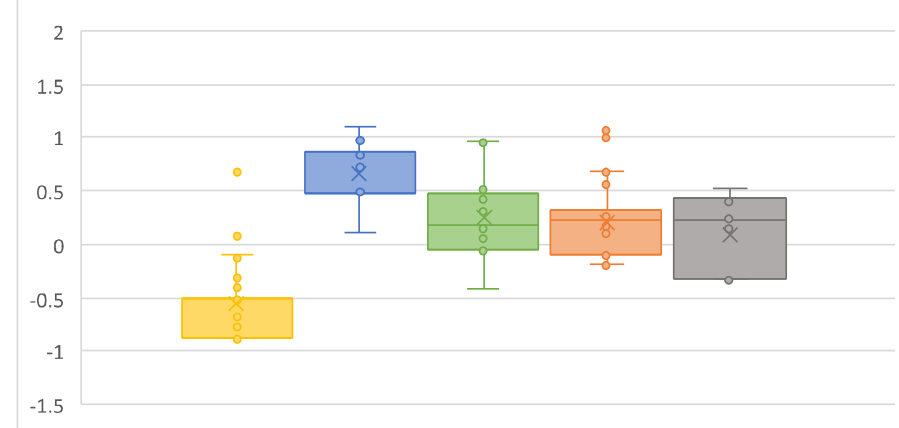

Figure 5. The qualitative characteristics of five groups in three axes.

Table 8. The characteristics of five groups under the three new axes.

\begin{tabular}{|c|c|c|c|c|}
\hline \multirow[b]{2}{*}{ Groups } & \multicolumn{3}{|c|}{ The Characteristics in Three Axes } & \multirow[b]{2}{*}{ SUM } \\
\hline & $\begin{array}{c}\text { First Axis Variety } \\
\text { of Play Types }\end{array}$ & $\begin{array}{c}\text { Second Axis } \\
\text { Accessibility of Play }\end{array}$ & $\begin{array}{c}\text { Third Axis } \\
\text { Initiative of Play }\end{array}$ & \\
\hline G1 & - & - & Exercise & Exercise/Physical play \\
\hline G2 & Less Variety & - & Creativity & Less Variety + Creativity \\
\hline G3 & - & Distant Tour & - & Distant Tour \\
\hline G4 & Variety & - & - & Variety \\
\hline G5 & - & $\begin{array}{l}\text { Natural Activity } \\
\text { Nearby }\end{array}$ & - & Natural Activity Nearby \\
\hline
\end{tabular}


The qualitative characteristics of each group are summarized in Table 8: G1 signifies low playability (less initiative of play); physical activity play mode-Exercise; G2 signifies less variety of play but high creative play mode; children can create a variety of ways to play-Less Variety and Creativity; G3 signifies non-daily play and distant, even remote, tour, travel, or sightseeing play by children's family-Distant Tour; G4 signifies variety of play including a kind of variety influenced by the addition of lots of natural elements-Variety; G5 signifies children's daily play; the nearby nature experience activity of play-Natural Activity Nearby.

Finally, the following conclusions (qualitative changing patterns in the passage of time) could be drawn based on the results mentioned above by combining the percentage trends of the times of the five groups in Figure 4:

Pattern 1 (trend of G1): physical play, in approximately 30 years from 1992-2018, rose and fell repeatedly and reached its peak in the early 1990s, mid-2000s, and the late 2010s, especially in 2018. It was obvious that this form of play was used over and over again and was not restricted by the times.

Pattern 2 (trend of G2): the combination of less variety and creativity related to play showed a growing trend in and before 2002, indicating that it had often been used for reference by designers to design spaces for children with less variety and creativity. However, there was a significant reduction after that until 2018. Instances were few, almost zero. It indicated that this way of play was still lacking in present-day urban life, because designers focused on improving the variety of play types often may be overlooking the creativity and playability (interest) of play. Consequently, this point could be further contemplated: the fun of play (playability) is not equal to the variety of play.

Pattern 3 (trend of G3): tourism and travel-style play with family for children was a minor consideration across all times, peaking in the early 1990s, and gradually decreasing with the passage of time.

Pattern 4 (trend of G4): the variety of play with diversity of natural elements showed an upward trend and increased sharply over almost 30 years, which indicated that with both research and practice, designers realized that the diversity of natural elements could bring out the variety of play types, as well as the importance of the existence of natural elements in designing.

Pattern 5 (trend of G5): feeling or being in contact with nature nearby, regardless of the time, presented low numerical values. In the early 2010s, there was a minor increase. It indicates that this type of play had not been the mainstream approach followed by designers to design for children's play.

Furthermore, in Table 7, the urban artificial play and nearby play had always been together, because the category scores were always close, which showed that this compound mode constituted the basic play styles, and it was often used by designers generally and daily. Examples of this include simple play equipment or small play tools that can be seen in parks or residential areas around the life circle.

By analyzing the selected works of JILA, we have learned that designers always take some aspects into account while designing for children, which include "Variety of Play Types," "Accessibility of Play," and "Initiative of Play," as the basic setting of child-related design considered axes in this study. It is clarified that "Exercise," "Less Variety and Creativity," "Distant Tour," "Variety," "Natural Activity Nearby constitute the five changing patterns and one normal basic combination from the three axes.

\section{Discussion}

The presented results that refer to children and play or playgrounds were considered as the designers' perspective. Whereas we recognize the importance of the presence of natural elements to add a variety of design elements into designing draw in order to improve the variety of play, we still need to contemplate how we can design fun, creative, and playable spaces for children. Here we show five changing patterns related to children's play and one basic combination wherever it can be seen. Thereby, the basic patterns, which are the "Exercise" of play, and the combination of "Proximity" and "Urban Artificial," are the general approaches used by designers to make a plan or design for children for an urban open space, because both of basic patterns have been at high levels of numerical 
value over time. On the other hand, this also shows that children's daily behaviors near the life circles are the basis of their play. It also has been inseparable from various artificial produced amusement rides or devices in modern society, such as some simple play equipment: jungle gyms, slides, pull up bars, swings, merry-go-round, and so on in residential area or urban parks, which corresponds to the findings of the studies mentioned above $[8,9,13,27]$.

"Exercise" (physical play activity) in play has also become stronger recently followed by the time, after rising and falling repeatedly. It is obvious that this style of play-just making children's bodies move around-was used over and over again and not restricted by time. Consequently, when further combining the 14 original categories with the results of Quantification Theory Type III and Cluster Analysis, the new point highlights the combination of Proximity and Urban Artificial—also clearly used frequently in daily life, because of their appearance in every decade of the past 30 years. Moreover, the play combination of Creativity and Position, less used by designers but with high playability, is almost the normal pattern appearing every decade, but it has fallen a little since 2014 and the least in 2018. This means that creating ways of play by children themselves (playability) does not conflict with the size or quality of playgrounds; it can also make children's play enjoyable just by setting up fun play facilities, planning changeable terrains with plants, establishing some adventure play equipment, or by other wonderful crazy thoughts for design in a certain place (Position). However, it has been decreasing recently. It is speculated that this may be because, in a fast-paced society, this kind of design related to children's play often requires high talent, whimsy, and the need to spend lots of time to investigate and analyze the place or residents' various life styles as well as their surroundings, and even trying new and advanced means to make design works more interesting. Therefore, simply adding a variety of elements to enrich children's play has become an efficient and common method for designing or planning. The increase of residential land for urban apartment complexes in recent years, and the increased awareness of the importance of natural elements have already decreased the "Creative" and "Position" play spaces. In the future, this will be an important consideration for designers. Therefore, it is appropriate to encourage talented designers to discover some interesting ways to make children themselves create, rather than to monotonously add a mass of elements to their designs. As for the increased awareness of the importance of natural elements in design, several previous studies $[4-6,29]$ mentioned in the introduction revealed that researchers have already paid attention to the addition of natural elements to improve variety. Even the practitioners-designers-agree, according to the results of Pattern 4 and Pattern 5, that the importance of nature-related play experiences has increased and may been increasing as before in the future.

Finally, two thoughts from this study are contemplated as follows: the variety of play is not exactly equal to interesting play (the playability), and the situation of over-designing is prevalent in modern society. People often equate the variety of play types with fun playable ways of play in design, which should be clearly recognized and considered from the children's perspective. Learning how to strike a proper balance, and not over-designing, could be explored in future studies.

\section{Conclusions}

By analyzing Play-Image components, 173 selected works were divided into five types, and the characteristics were revealed in terms of the following changes over the past few decades:

First of all, with regard to general pattern, the combination of Proximity and Urban Artificial occurs frequently in daily life, and it appears in every decade over the past 30 years. The combination of Creativity and Position, and fewer play styles but high playability, is also a general pattern that appears every decade, but has recorded a drop since 2014.

Second, the landscape designers in Japan have already recognized the importance of natural elements to promote the diversity of play, remaining in sync with research on children's play style and playgrounds. As time passed, this seemed to increase.

Third, "Exercise" in play has become stronger recently, followed by time. 
Fourth, a doubt is emphasized by this study that designers may not consider "variety of play" to exactly equal "interest of play." Designers should not only increase the variety of play styles by improving natural elements, but also focus on how to make playgrounds more playable and how to encourage children to play and enjoy themselves from children's perspectives. Designers improving playability, "Creativity," and "Position" with the advancement of high technology, such as an Inflatable Film Cloud on the ground for children to climb and jump on, and creating more playable adventures, exploratory play equipment, and changeable play spaces, will be a future trend.

Fifth, the variety of elements used and the enhancement of playability should be balanced by designers while taking into consideration the sustainability factor. How to avoid over-designing may be the future research direction.

The characteristics mentioned above were the obvious patterns that describe the changing consideration of designers over decades with regard to children's play and the benefit of designing spaces for children. On the other hand, besides the diversity, there should also be a relationship between spatiality and playfulness among these patterns, which—with improvements in technology—could make playgrounds more attractive for children in urban areas. Consequently, it was understood that the concrete consideration points mentioned above influenced children's outdoor playfulness and developmental playing according to the characteristics of children's activity, space property, and other requirements for functions that would provide a design reference for professionals and designers while planning playgrounds for children. Further studies will be conducted in this field in the future.

Author Contributions: Conceptualization, Q.Q. and A.S.; methodology, Q.Q., K.W.N., K.Y. and A.S.; software, K.W.N.; validation, Q.Q., K.W.N., K.Y. and A.S.; formal analysis, Q.Q.; investigation, Q.Q.; data curation, Q.Q., K.W.N., K.Y. and A.S.; writing—original draft preparation, Q.Q.; writing—review and editing, Q.Q. and K.W.N.; supervision, A.S.

Funding: This research received no external funding.

Conflicts of Interest: The authors declare no conflict of interest.

\section{References}

1. Kim, W.H. The importance of playing in the city, a comparison of children's playgrounds. Erasmus Mundus Master Course in Urban Studies [4CITIES] 2016-2018. 2018. Available online: https:/ / www.4cities.eu/wpcontent/uploads/2018/10/MAThesis_4Cities_KIM_WAN_HEE.pdf (accessed on 30 March 2019).

2. Frost, J.L. Play and Playscapes; Delmar Publishers: New York, NY, USA, 1992.

3. Cunningham, C.J.; Jones, M.A. The Playground: A confession of failure. Built Environ. 1999, 25, 11-17.

4. Gotoh, C.; Shimomura, A.; Kumagai, Y.; Ono, R. A study on the relation between children's play and space characteristics in Rinsinomori and Koishikawa Botanical garden. J. Jpn. Inst. Landsc. Archit. 1996, 59, 137-140. [CrossRef]

5. Okada, Y.; Nakamura, O.; Kinoshita, I.; Saito, Y. The case study on stages and diversity of catching insects in children's play in the city area and rural area. J. Jpn. Inst. Landsc. Archit. 2001, 64, 883-886. [CrossRef]

6. Ye, K.-R. The relationship between change of children's nature experiences and the characteristics of their residential areas. J. Jpn. Inst. Landsc. Archit. 1995, 58, 245-248. [CrossRef]

7. Shimizu, M. Ohya Reigo: The first green planner pf city (landscape architects in Japan). J. Jpn. Inst. Landsc. Archit. 1997, 60, 203-206.

8. Senda, M.; Miyamoto, S. Research for the structure of children's play environments: Space logic of the play environment. Trans. Archit. Inst. Jpn. 1981, 303, 103-109. [CrossRef]

9. Masui, H.; Endoh, Y.; Satou, S.; Ishihara, K.; Kanbe, Y.; Yajima, T.; Renbutsu, Y.; Takemura, K.; Fujiwara, N.; Fujii, A. Evaluating space around the home from the view point of children's play opportunity: A study on space around the low-rise home from the view point of housing environment unit (4). Summ. Tech. Pap. Annu. Meet. Archit. Inst. Jpn. 1983, 58, 1245-1246.

10. Nakamura, O. The Place Where Child Met a Crime? Crime Space Realities, Factors, Countermeasures; Shobunsha Publishers: Tokyo, Japan, 2000; pp. 88-100.

11. Senda, M. Child and the Play; Iwanami Shoten Publishers: Tokyo, Japan, 1992.

12. Kinoshita, I. Play and the Town of Ecology; Maruzen Publishing: Tokyo, Japan, 1996; pp. 35-67. 
13. Misawa, N.; Saio, N.; Aizawa, H.; Yun, Y.-S.; Goto, T. The pattern and the selectivity in securing outdoor play spaces by elementary students within their residential areas: A study on securing methods of outdoor play spaces by elementary students living in urban residential areas part 1. Summ. Tech. Pap. Annu. Meet. Archit. Inst. Jpn. 2001, E-1: Archit. Plan. Des. I, 151-152.

14. Ayako Naka+TeamM Produced by NOMURA Co., Ltd. Designing Spaces for Children and Adults [Bilingual]; Sangakusha Publishers: Tokyo, Japan, 2018; pp. 18-19.

15. Hu, M.; Chen, R. A framework for understanding sense of place in an urban design context. Urban Sci. 2018, 2, 34. [CrossRef]

16. Norbert-Schulz, C. Genius Loci. Towards a Phenomenology of Architecture; Rizzoli: New York, NY, USA, 1980.

17. Senda, K. Benefits of school grounds improvement from the viewpoint of pupils' behavior maps during playtime at Sakata Primary School. J. Jpn. Inst. Landsc. Archit. 2005, 68, 837-842. [CrossRef]

18. Yamamoto, M.; Shimorura, A.; Ono, R.; Kumagai, Y. A study on the characteristics of park use at Shinjuku Gyoen according to age brackets and the factor of selection of space. J. Jpn. Inst. Landsc. Archit. 1999, 62, 627-630. [CrossRef]

19. Ohono, M.; Hattori, T.; Shinji, I. A study on park debut from the park use of mothers and children. J. Jpn. Inst. Landsc. Archit. 1998, 61, 785-788. [CrossRef]

20. Tsneg, S.; Asakawa, S. Changes of children's outdoor play activities and consciousness of play space in winter Sapporo. J. Jpn. Inst. Landsc. Archit. 2004, 67, 703-708. [CrossRef]

21. Tagawa, S. Characters of planning and play activities for indoor playgrounds of parks in snowy and cold region. J. Jpn. Inst. Landsc. Archit. 2007, 70, 551-554. [CrossRef]

22. Saio, N.; Aizawa, H.; Goto, T.; Yun, Y.-S. A study on planning and improvement of outdoor spaces in public elementary school as seen by utilization of environment with natural materials. Trans. Archit. Inst. Jpn. J. Archit. Plan. Environ. Eng. 2002, 554, 131-138.

23. Yang, X.; Senda, M.; Yata, T. Characteristics of streets for children to play, analysis of data from observation and interview surveys in Beijing. Trans. Archit. Inst. Jpn. J. Archit. Plan. Environ. Eng. 2005, 70, 103-110.

24. Shen, Y.; Kinoshita, I. Study on the characteristic about transition of children's outdoor play space in high-rise housing estate of Beijing. J. Jpn. Inst. Landsc. Archit. Line 2011, 4, 48-52.

25. Saio, N.; Hase, M. Diversification of place-making for children and compatibility of "safety and security" with "comfortable spaces": A study on "place-making" for children after school. Trans. Archit. Inst. Jpn. J. Archit. Plan. Environ. Eng. 2007, 72, 33-39.

26. Igarashi, Y. The relation between physical components and evaluation of users in children's park. J. Jpn. Inst. Landsc. Archit. 1983, 46, 87-92. [CrossRef]

27. Yun, Y.-S.; Saio, N.; Aizawa, H.; Goto, T. A study on the characteristics of children's place to stay and environmental factors on the outdoor space in public elementary school site: As a case study focusing on the actual condition of children's activity in residential areas. Trans. Archit. Inst. Jpn. J. Archit. Plan. Environ. Eng. 2003, 68, 149-156.

28. Kaizu, Y.; Ishimitsu, K.; Shimomura, A. A study on the structure of recognition of wildlife through nature observation. J. Jpn. Inst. Landsc. Archit. 1996, 59, 141-144. [CrossRef]

29. Horiuchi, M.; Fukamachi, K.; Oku, H.; Okada, K. Early Showa Period use of natural resources and natural space in child play in a rural community in the western part of Shiga Prefecture, Japan. J. Jpn. Inst. Landsc. Archit. 2009, 72, 673-678. [CrossRef]

30. Kubota, T.; Said, I.; Rasidi, M.H.; Sakamoto, C. Development of an environmental education program using place-based outdoor learning for elementary school children in Malaysia: A pilot project in Johor Bahru. Trans. Archit. Inst. Jpn. J. Environ. Eng. 2013, 78, 203-212.

31. Fjùrtoft, I.; Sageie, J. The natural environment as a playground for children Landscape description and analyses of a natural playscape. Landsc. Urban Plan. 2000, 48, 83-97. [CrossRef]

32. Shimomura, Y.; Masuda, N.; Abe, D.; Yamamoto, S.; Suzuki, K. Study on resident's behavior of block park in neighborhood. J. Jpn. Inst. Landsc. Archit. 1995, 58, 217-220. [CrossRef]

33. Suzuki, S.; Kurita, K.; Suzuki, S.; Ito, K.; Niwa, Y. A study on the relationship between shape and a view from inside of the park: The block-park in Ota-ku, Tokyo. Summ. Tech. Pap. Annu. Meet. Archit. Inst. Jpn. 2015, F-1: Urban Plan, 1043-1044.

34. Tanaka, N.; Maeda, H. Urban block parks in Tokyo central: Case study of Minato city. Summ. Tech. Pap. Annu. Meet. Archit. Inst. Jpn. 2015, F-1: Urban Plan, 979-980. 
35. Yata, T.; Takagi, K.; Senda, M. Increasing children users in public parks through planning guidelines: Based on multiple regression analysis of use data from on-site observations. Child Youth Environ. Stud. 2014, 10, 59-67.

36. Zhang, J. The diagnosis methods in planning and designing (10): Quantification Theory Type III. J. Chin. Landsc. Archit. 2000, 16, 79-83.

37. Dai, F.; Zhang, J.; Tashiro, Y. A study on space characteristics of the places for Taiji Boxing in parks and squares of Wuhan City, China. J. Jpn. Inst. Landsc. Archit. 2006, 69, 605-608. [CrossRef]

38. Naito, H. Children's play environment in residential neighborhoods, relationship between playing activities and space/element. Bull. Jpn. Soc. Sci. Des. 1987, 61, 5-12.

39. Terauchi, M.; Kaga, H.; Shimomura, Y.; Masuda, N. Study on environmental factors to form children's play in the outdoor space in 30s in the Showa Era. J. Jpn. Inst. Landsc. Archit. 2006, 69, 659-664. [CrossRef]

40. Yoshino, M.; Furuya, K.; Suzuki, K. Childhood outdoor activities and nature experiences which remain in university students' memories. J. Jpn. Inst. Landsc. Archit. 2011, 74, 591-596. [CrossRef]

41. Miyazono, M.; Tanaka, C.; Hayashida, D.; Adachi, K. A study of the children's indoor and outdoor play environment during summer vacation: A case study in Minabe City on Wakayama. Summ. Tech. Pap. Annu. Meet. Archit. Inst. Jpn. 2004, E-2: Archit. Plan. Des. II, 419-420.

42. Ougiya, K.; Uno, H.; Kawata, R.; Horii, M.; Kanaya, K.; Oota, K. A study on the children's daily living and play environment: Part 4: The parents and children's consciousness of winter and the kind of children's play in winter. Proc. Archit. Inst. Jpn. Hokkaido Archit. Res. Conf. 1999, 72, 329-332.

(C) 2019 by the authors. Licensee MDPI, Basel, Switzerland. This article is an open access article distributed under the terms and conditions of the Creative Commons Attribution (CC BY) license (http://creativecommons.org/licenses/by/4.0/). 